DOI: 10.20472/IAC.2018.935.051

KRISTA UIBU

Institute of Education, University of Tartu, Estonia

MERIKE KASEORG

School of Economics and Business Administration, Estonia

\title{
PRIMARY SCHOOL TEACHERS' BELIEFS ABOUT DISCIPLINES OF LEADERSHIP A LEARNING ORGANIZATION BY INDIVIDUAL AND ORGANISATIONAL LEVELS
}

\begin{abstract}
:
According to Senge (1990) the leadership is based on five disciplines. On the basis of their focus the disciplines can be divided into two categories: the personal level (personal mastery and mental models) and the organizational level (shared vision and team learning). Systems thinking involves both levels. The aim of this study was to find out which disciplines of leadership of a learning organization are prevailing in the teachers' beliefs, in order to develop a leadership model of an effective educational institution at personal and organizational levels. The interviews of 45 primary school teachers from 28 Estonian schools were analyzed by the method of targeted thematic analysis. Both, group- and person-oriented approaches were used to investigate the differences between the average results of groups and between the teachers with different profiles (Bergman et al., 2003; Cohen et al., 2007). It appeared that the personal mastery as well as mental models appeared substantially more frequently in teachers' interviews than the disciplines related to the organizational level (systems thinking, shared vision and team learning). However, the frequency of mentioning systems thinking was especially low, which may be related to the lack of the relevant theoretical knowledge of teachers. The model of effective management of an educational institution created on the basis of the results of this study.
\end{abstract}

\section{Keywords:}

learning organization, disciplines of leadership, teacher's profile, targeted thematic analysis

JEL Classification: 121, 129, 043 